\title{
Interventions for caries in primary teeth; mapping reported outcomes in clinical trials over the last 30 years
}

\author{
Nicola P T Innes ${ }^{1 *}$, Felicity Borrie ${ }^{1}$, Neeraj Gugnani ${ }^{2}$, Alex Keightley ${ }^{1}$, Thomas J Lamont ${ }^{1}$, Zoe Marshman ${ }^{3}$, \\ Ruth Santamaria ${ }^{4}$, Falk Schwendicke ${ }^{5}$ \\ From The 4th Meeting of the Core Outcome Measures in Effectiveness Trials (COMET) Initiative \\ Rome, Italy. 19-20 November 2014
}

\section{Background}

Dental caries (tooth decay) is the most prevalent disease in school age children and carries a burden of pain and infection. Clinical trials investigating interventions (fillings and other caries management techniques) to mitigate these have no agreed core outcome set making research design difficult and complicating evidence synthesis. The first step in addressing these issues is to map the current status.

\section{Research question}

What outcomes have been measured in clinical trials investigating management of carious primary teeth over the past 30 years?

\section{Objectives}

- Identify and categorise outcomes/outcome measures of all published randomised and controlled clinical trials investigating restoration of primary teeth in children, including pulp therapy;

- Assess quality of reporting; and

- Look for trends/gaps/patient reported/patient oriented outcomes.

\section{Inclusion}

- Population: Individuals 6 months to 14 years (Human studies)

- Interventions: Management techniques for carious primary teeth and pulp therapy at tooth, patient, clinician or practice level.

- Comparisons/Control: No intervention/different interventions/Self

* Correspondence: n.p.innes@dundee.ac.uk

${ }^{1}$ University of Dundee, Dundee, DD1 4HR, UK

Full list of author information is available at the end of the article
- Outcome: all outcomes

- Study design: randomised and controlled clinical trials

Search strategy for Cochrane Oral Health Group's Trial register and Cochrane Central Register of Controlled Trials (CENTRAL): (((((“Dental Restoration, Permanent"[Mesh] OR “Dental Restoration, Temporary"[Mesh]) OR “Dental Cements" [Mesh]) OR "Pulp Capping and Pulpectomy Agents"[Mesh]) OR "Resins, Synthetic"[Mesh]) OR "Dental Pulp Capping"[Mesh]) OR "Pulpectomy" [Mesh]) OR "Pulpotomy"[Mesh] AND (Clinical Trial [ptyp] AND (“1983/11/01"[PDAT] : “2013/11/01”[PDAT]) AND "humans"[MeSH Terms] AND ("infant" [MeSH Terms] OR "child"[MeSH Terms] OR "adolescent" [MeSH Terms]))

\section{Data extraction and analysis}

Titles/abstracts will be reviewed independently and in duplicate; obtain manuscripts for those meeting inclusion criteria, or where this is unclear; piloted proforma for data extraction, independently and in duplicate $\left(3^{\text {rd }}\right.$ person to resolve disagreement).

\section{Data management}

Data will be entered into a bespoke Microsoft Access database; export to SPSS or Microsoft Excel.

\section{Data analysis}

Outcomes/outcome measures listing; Independent categorisation by 3 researchers; consensus will be reached through discussion; Reporting quality will be measured according to Cochrane methodology; Outcome/outcome measure categories will be mapped against intervention 
type, year of publication, country of publication and author group; There will be discussion to interpret the findings, agree trends and look for gaps.

\section{Authors' details}

'University of Dundee, Dundee, DD1 4HR, UK. ${ }^{2}$ DAV Centenary Dental College, Haryana, India. ${ }^{3}$ University of Sheffield, Sheffield, UK. ${ }^{4}$ University of Greifswald, Greifswald, Germany. ${ }^{5}$ Charité - Universitätsmedizin Berlin, Germany.

Published: 29 May 2015

doi:10.1186/1745-6215-16-S1-P31

Cite this article as: Innes et al: Interventions for caries in primary teeth; mapping reported outcomes in clinical trials over the last 30 years.

Trials 2015 16(Suppl 1):P31.

Submit your next manuscript to BioMed Central and take full advantage of:

- Convenient online submission

- Thorough peer review

- No space constraints or color figure charges

- Immediate publication on acceptance

- Inclusion in PubMed, CAS, Scopus and Google Scholar

- Research which is freely available for redistribution

Submit your manuscript at www.biomedcentral.com/submit
Ciomed Central 